\title{
EXPERIMENTAL STUDY ON SUSPENDED SEDIMENT TRANSPORT TO REPRESENT TIDAL BASIN MANAGEMENT
}

\author{
Rocky TALCHABHADEL ${ }^{1}$, Hajime NAKAGAWA ${ }^{2}$, Kenji KAWAIKE ${ }^{2}$ \\ ${ }^{1}$ Student member of JSCE, Ph. D. Student, Dept. of Civil and Earth Resources Engineering, Kyoto University \\ (Shimomisu, Yoko-oji, Fushimi-ku, Kyoto 612-8235, Japan) \\ ${ }^{2}$ Member of JSCE, Dept. of Civil and Earth Resources Engineering, Kyoto University
}

(Shimomisu, Yoko-oji, Fushimi-ku, Kyoto 612-8235, Japan)

\begin{abstract}
The main purpose of Tidal Basin Management is to get suspended sediment deposits gradually under a controlled system. When a cut is made at an appropriate point of embankment, muddy water enters the tidal basin during high tide, depositing a portion of suspended sediments on the basin before flowing back towards the ocean during low tide. An attempt has been made to study through laboratory experiments to precisely look into the suspended sediment transport at entrance of beel. With change of outflow at side basin or tidal beel and change of sediment concentration at inlet, the transportation and deposition of sediment are investigated. Transportation and deposition of suspended sediment mainly depend upon direction of flow and magnitude of outflow discharge at side basin. Better understanding of sediment transport phenomena increases the effectiveness of Tidal Basin Management.
\end{abstract}

Key Words: TBM, Beel, Side Basin, Sediment Concentration

\section{INTRODUCTION}

Bangladesh is the biggest delta of the world formed by sediments carried by the Ganges-padma, Brahmaputra-jamuna and Surma-meghna river system. Life in Bangladesh has been, is and will always be defined by the vast quantities of water and sediment that flow through the country ${ }^{1)}$. In fact, the entire country is formed by the sediments from the Himalayas and the Bay of Bengal ${ }^{2}$. The GangesBrahmaputra River System (Fig.1) carries the world's highest annual sediment load at one billion tons $^{3), 4)}$.

Construction of numbers of polders is one of the flood resilient approach. The siltation problem in rivers causes riverbeds to become higher than the adjacent crop lands, and vast area lower than the polders are permanently kept water logged. The drainage congestion and sedimentation has been major issues over the years in river basins of Bangladesh. The decrease of flushing flow from upstream and substantial reduction of tidal flooding area along the river by constructing polders caused severe siltation over a long stretch of the river.

Introduction of certain areas as tidal flood plain to deposit sediment on the floodplain rather than on the river itself and rotation of that lowlands is current practice of tidal basin management (TBM). Beel is low-lying depression in the floodplain that generally contain water throughout the year ${ }^{5}$. The present practice of TBM is to connect the river with the selected tidal beel by constructing a link canal ${ }^{6}$. This is a natural water management process with very little human interventions but it needs strong participation and consensus with a great deal of sacrifice by the stakeholder for a specific period (3 to 5 years or even more) depending on the tidal volume and the area of the beel ${ }^{7)}$. Most studies focused on sediment deposition relating to supply of varying inflow discharge. This research tries to analyze various scenarios under constant inflow discharge. It aims to study sediment transport and deposition in the tidal beel to effectively understand TBM.

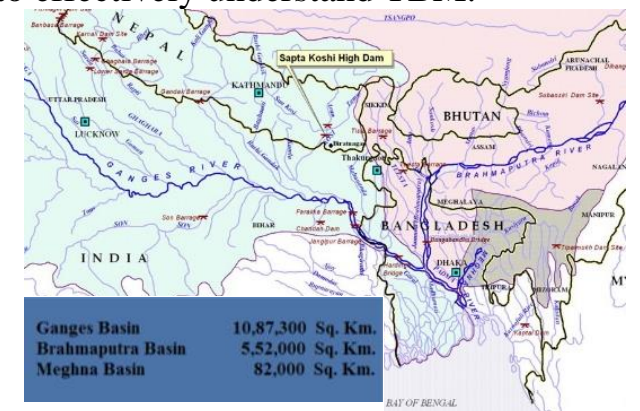

Fig. 1 The catchments of the Ganges, Brahmaputra and Meghna Source: www.jrcb.gov.bd/image/Basin_map.jpg 


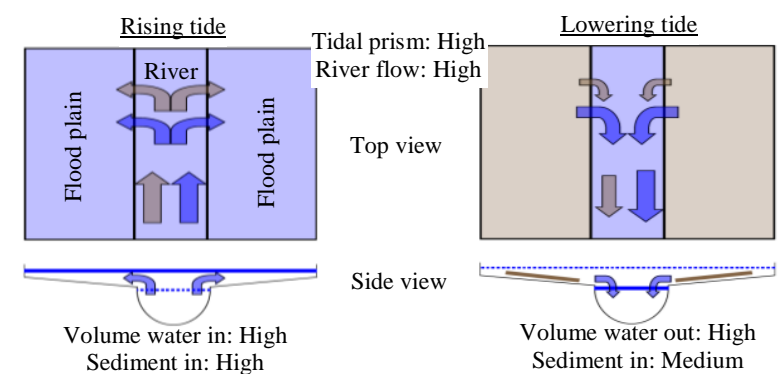

Fig.2 Morphological state of rivers before the coastal embankment project $^{1)}$

\section{SEDIMENT TRANSPORT PROCESS}

(1) Pre-coastal embankment project

Before the coastal embankment project, which commenced in the 1950s, the quantity of water flowing through the rivers during high and low tide is high; the volume available for the water to fill up (in the floodplains) is very large. In other words: the tidal prism of these rivers was very high, making the sedimentation process relatively slow. Sedimentation occurred mainly on the low-lying floodplains (Fig.2).

\section{(2) Post-coastal embankment project}

Under the USAID funded project, 37 polders and 1566 kilometers of embankments were constructed in the southwest delta ${ }^{8}$. The polders were considered to be successful in their early years of operation, because they decreased floods and created stability in agricultural areas $^{2}$. The polders also dramatically decreased the volume of tidal water stored in the floodplains, because the embankments prevented water from entering them. Fig.3 shows the process of sedimentation even slow has led to a gradual buildup of sediment in the rivers.

\section{(3) Drainage congestion late 1980s}

In the 1980s, riverbed sedimentation started to cause drainage congestion. The siltation problem in rivers caused riverbeds to become higher than the adjacent crop lands and vast area lower than the polders became permanently water logged.
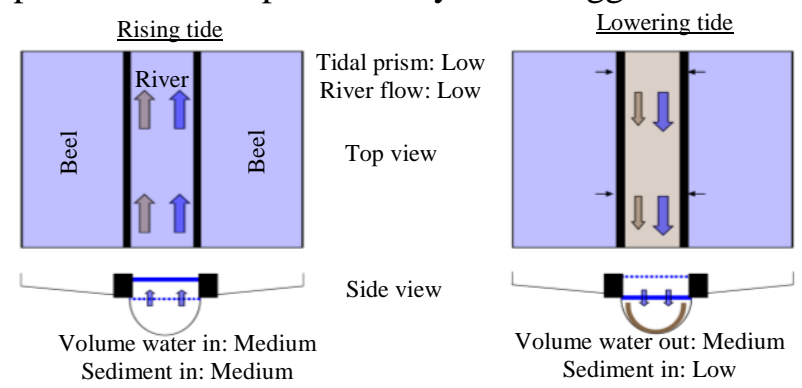

Fig.3 Morphological state of rivers after the coastal embankment project $^{1)}$

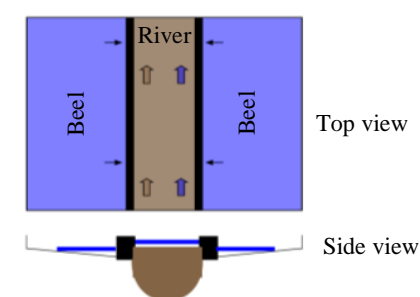

dal prism: Very Low River flow: Very Low Sediment settles in river

Fig.4 Development of waterlogging in beels adjacent to 'dying' river ${ }^{1)}$ Top view

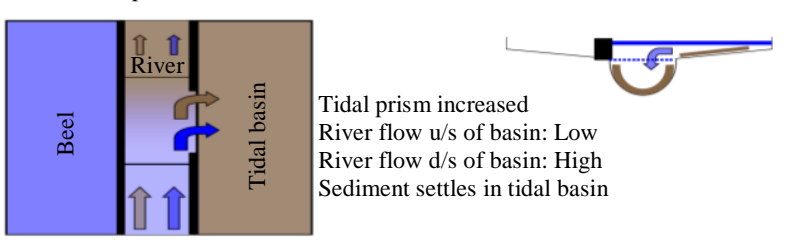

Fig.5 River morphology under tidal river management ${ }^{1)}$

Fig.4 shows that the interaction between flood plain and river has been cut off. Waterlogging caused considerable economic, social and environmental problems. Especially during monsoon season when precipitation is extremely high, waterlogging was big problem in beels.

\section{(4) Tidal River Management}

On October 29th, 1997, the local population at beel Bhaina cut their embankment turning the 1000 hectare beel into a tidal basin as they hoped that the sediment-laden water would raise the land of their beel and thereby improve drainage ${ }^{9)}$.

Fig.5 shows how sediment settles in beel after introduction of certain area as tidal basin. As the tidal prism increased, the cross section of the river downstream of selected beel increased. Sediments started depositing on the floodplain rather than on the river itself. In case of beel Bhaina, sediment was deposited raising its land level by an average of 78 centimeters $^{10)}$.

\section{(5) TBM}

The "rotating basin" option was the best from an environmental perspective. This natural water management process with very little human interventions where it needs strong participation and consensus with a great deal of sacrifice by the stakeholders for a specific period is TBM.

The Bangladesh Water Development Board (BWDB) and the Institute for Water Modelling (IWM) have been conducting research in the area and have come up with a rotational tidal basin plan, in order to maintain the tidal prism in the Hari river and prevent future drainage congestion ${ }^{11)}$ (Fig.6). 


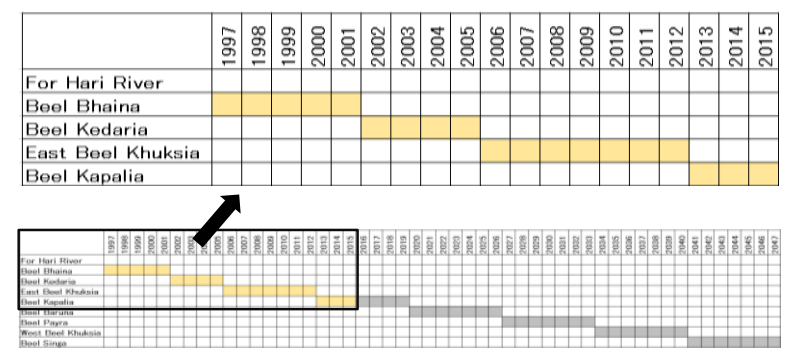

Fig.6 The IWM plan for rotational tidal basins in the HariMukteswari river ${ }^{11}$ )

\section{OBJECTIVE OF RESEARCH}

The aim of this research is to study the suspended sediment transport and deposition in the tidal beel to effectively understand tidal basin management. Suspended sediment transport plays an important role in the evolution of coastal environment. Hence, observation and modeling of suspended sediment concentration (SSC) is of immense interest to coastal oceanographers, engineers and coastal zone management authorities ${ }^{12}$. In Bangladesh the suspended load of a river carries the majority of the sediment, while bedload transport accounts for approximately $10 \%$ of the suspended load ${ }^{13)}$.

In this context, an attempt has been made to study through laboratory experiments to precisely look into the suspended sediment transport. The selected flume is meandering in nature and side basin is attached with flume which represents the entrance of tidal beel in TBM. Side basin in flume is equipped with changing outflow discharge to represent nature of different tidal beel. The main objective of the research is to study transportation of sediment and monitor its deposition in side basin in different conditions by varying outflow discharge at side basin and varying sediment supply at source.

\section{EXPERIMENTAL EVALUATION}

The experiments were carried out in a flume located at the Ujigawa Open Laboratory (UOL) of Disaster Prevention Research Institute (DPRI), Kyoto University. The experimental facility is illustrated in Photo.1 and schematic view of the experimental setup is shown in Fig.7. Several parameters were measured during the experimental studies, namely: 2D water surface velocity by PIV techniques, velocity by electromagnetic current meter, bed profile by laser displacement sensor, surface water level by ultrasonic sensor and water discharge by bucket method.

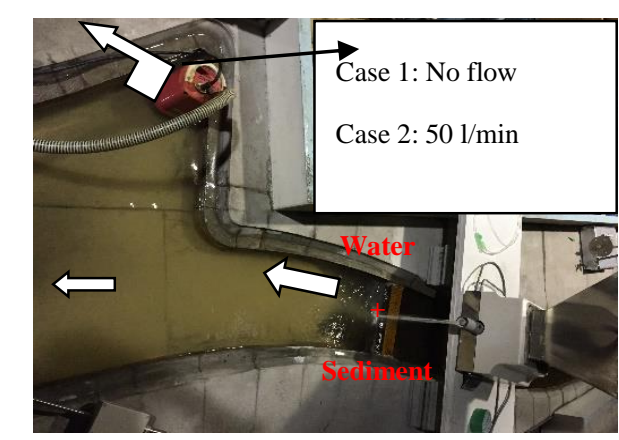

Photo.1 Experimental facility

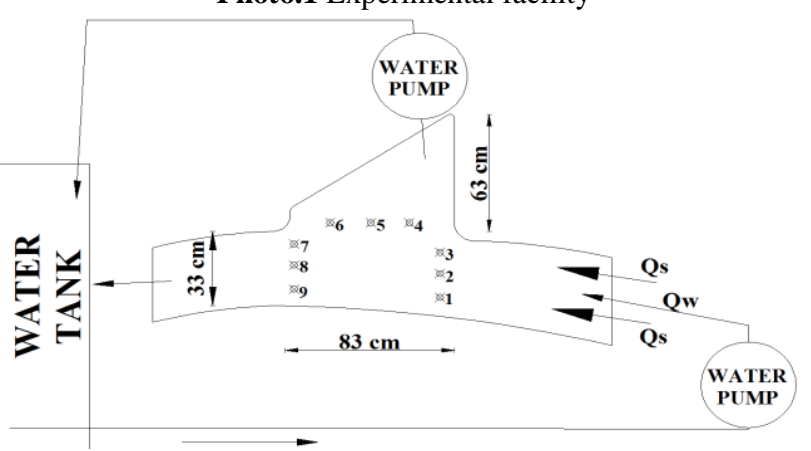

Fig.7 Schematic view of the experimental setup

The flume used is reinforced concrete flume of re-circulating type with wooden base at bottom where water flows. The shape of side basin is limited to triangular shape particularly in this research due to unavailability of space. 3 portions were attempted to study precisely. They are inlet, side basin and outlet. 9 sampling points namely $1-9$ representing inlet by 1-2-3, side basin/tidal beel by 4-5-6 and outlet by 78-9 as shown in Fig.7 were adopted to study sediment behavior. All experiments were conducted using a constant flow discharge of $125 \mathrm{l} / \mathrm{min}\left(\mathrm{Q}_{\mathrm{w}}\right)$ in experimental flume, referred to as inflow and were limited to fixed bed . Dry sediment of mean diameter equal to $80 \mu \mathrm{m}$ and density $1.76 \mathrm{gm} / \mathrm{cc}$ was fed from adjustable sediment feeder.

Firstly two cases were investigated as Case 1 where outflow discharge from side basin was not allowed to flow and Case 2 where discharge of 50 $1 /$ min was allowed to flow using water pump. The maximum rate that can be given from sediment feeder available in laboratory is $110 \mathrm{gm} / \mathrm{min}\left(\mathrm{Q}_{\mathrm{s}}\right)$. To understand direction of sediment flow and final deposited bed level, the maximum rate was used in both cases for 4 hours. Turbidimeter was used in mentioned 9 sampling points to take concentration data continuously. Using siphon pipe of $4 \mathrm{~mm}, 500$ $\mathrm{ml}$ of water was drawn in every 30 min taking a sample at inlet (1-2-3), side basin (4-5-6) and outlet (7-8-9) $2 \mathrm{~cm}$ below water surface to calculate concentrations after filtration then weighing and finally to make comparison with turbidimeter. 
For Particle Image Velocimetry (PIV) measurement, the flow was seeded with powdered particles (PVC, polyvinyl chloride powder) with mean diameter equal to $50 \mu \mathrm{m}$. Sony HD camera was used to record the images. The PIV technique determines the velocity of water flow and its flow direction indirectly by measuring the velocity of tracer particles within the flow. Final bed level data were measured using laser displacement sensor. The output data of bed level measurements are analogical voltage values. They were saved in laptop computer using a data collection system (A/D conversion card - Keyence NR-110 and data logger software). Before the bed level measurement a calibration of equipment with predefined thickness as reference levels were used to determine relation between the voltages registered and measured bed level.

Secondly the outflow discharges of side basin were varied. Different cases from 0, 10, 25, 50, 65, $80 \mathrm{l} / \mathrm{min}$ were investigated for an hour each to understand transportation phenomena of suspended sediment. Sediment supply of $50 \mathrm{gm} / \mathrm{min}$ was allowed.

Finally adjusting speed and aperture of sediment feeder, $10,25,50,65,85,95,110 \mathrm{gm} / \mathrm{min}$ dry sediment were supplied with outflow discharge at side basin kept constant $50 \mathrm{l} / \mathrm{min}$ for an hour each to study the relationship of sediment concentration at side basin and outlet with sediment concentration at inlet. Same 9 sampling points were adopted to take measurements for sediment concentration.

\section{RESULTS}

In case 1 water discharge is confined towards outlet so most of the sediment is deposited on the way towards the outlet and very little sediment enters into side basin. But in case 2 around 40-50 \% of flow is towards side basin so more sediment is deposited in side basin. The scenario of final bed level measured from laser displacement sensor after 4 hours of experiment for both the cases is shown in Fig. 8.

Change in elevation between two cases is also calculated to see which parts of sediments that have been deposited in case 1 are transported towards side basin in case 2 . Up to $26 \mathrm{~mm}$ of extra sediment deposition has been seen in side basin when water is allowed to flow from side basin (Fig. 9). It clearly shows that more the tidal flow in tidal basin more will be sediment transport and deposition.

In Fig. 10, photos in left sides are at a time of initiation of PIV and right sides are during PIV operation in both the cases. The flow direction is directed towards outlet in case 1 and towards side basin in case 2 .

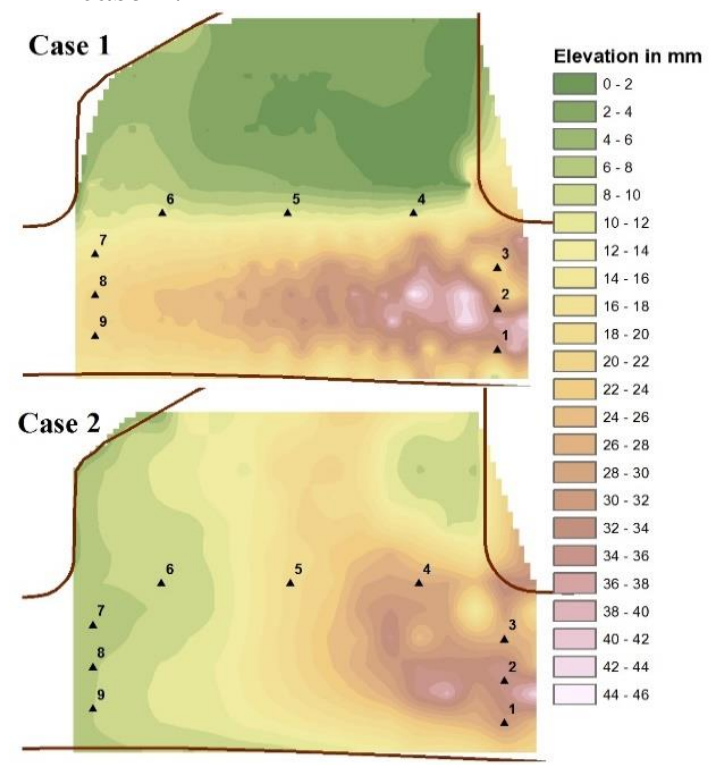

Fig.8 Final bed level in case1 and case2

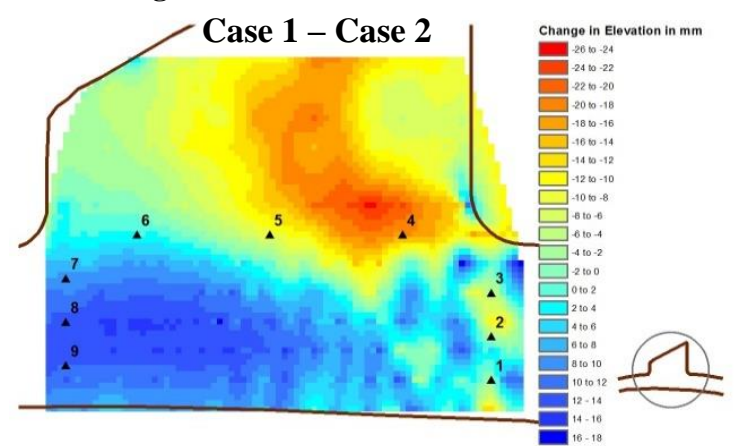

Fig.9 Change in elevation between two experimental cases
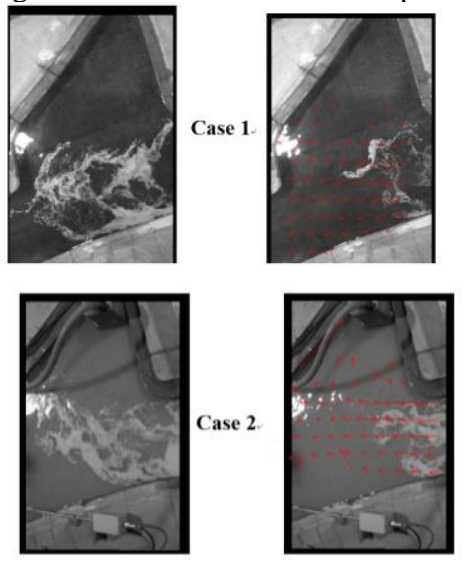

Fig.10 Surface flow visualization using PIV technique

In real scenario as in Bangladesh, transported sediment is finally deposited inside beel. But in this experiment, entry of tidal beel is only represented by side basin and whole tidal beel has not been incorporated. Thus sediment concentration is taken as primary indicator for this research rather than deposited thickness of sediments. 

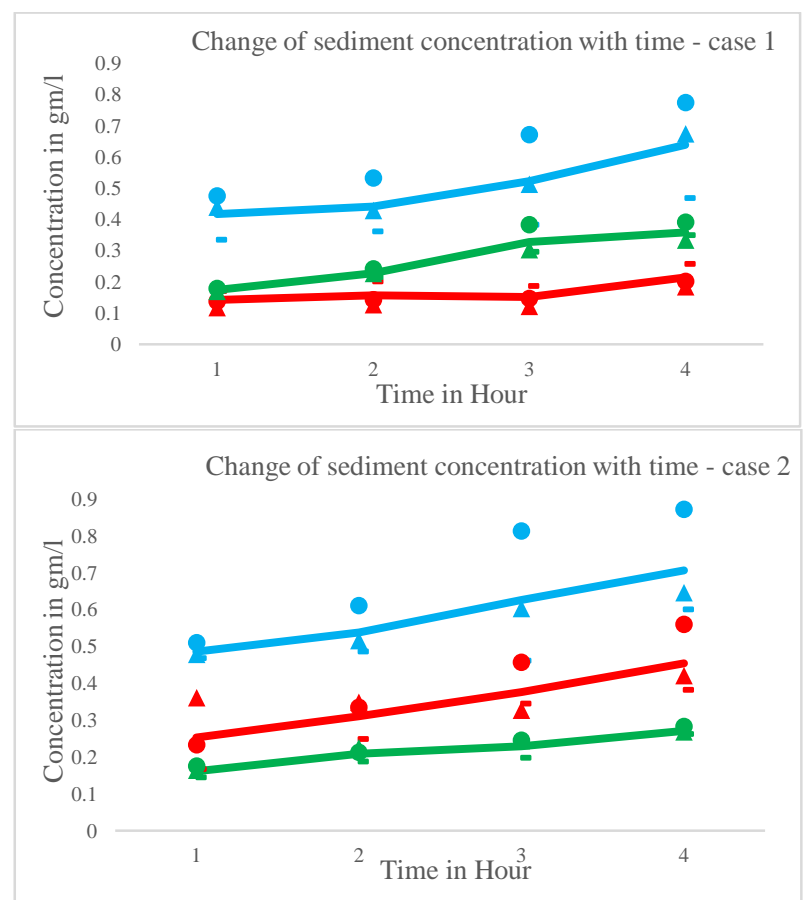

Fig.11 Sediment Concentration at 9 sampling points for case 1 and case 2

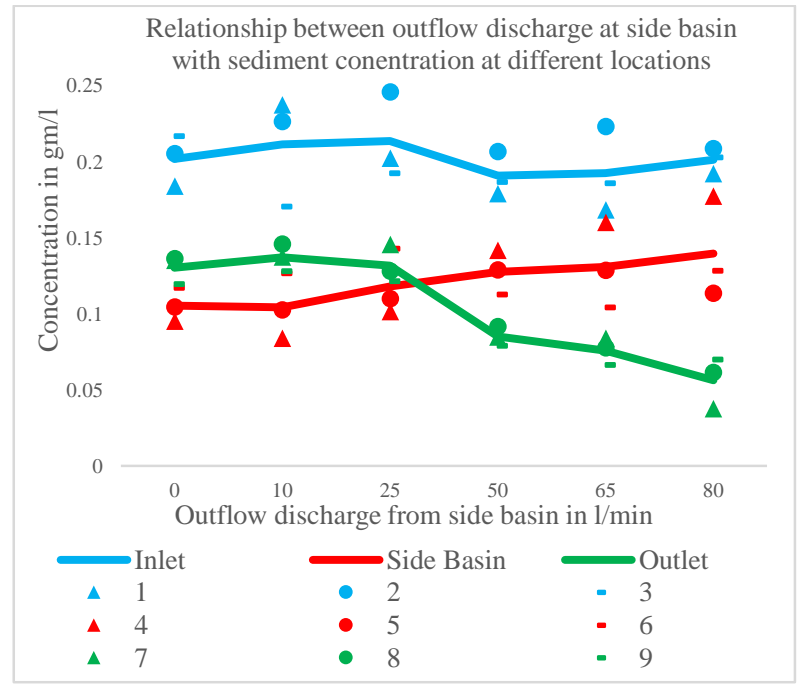

Fig.12 Sediment concentration at 9 sampling points with varying outflow discharge from side basin

The average value of water depth is $9.05 \mathrm{~cm}$ and average flow velocity is $6.97 \mathrm{~cm} / \mathrm{s}$. Even at the beginning of experiment it doesn't have any bed load, but sediment is deposited during experiment and it behaves as bed load which makes sediment concentration to increase with time in all sampling points as shown in Fig. 11. In case 1 sediment concentration at outlet (7-8-9) is greater than sediment concentration at side basin (4-5-6) whereas in case 2 sediment concentration at side basin (4-5-6) is greater than sediment concentration at outlet (7-89).

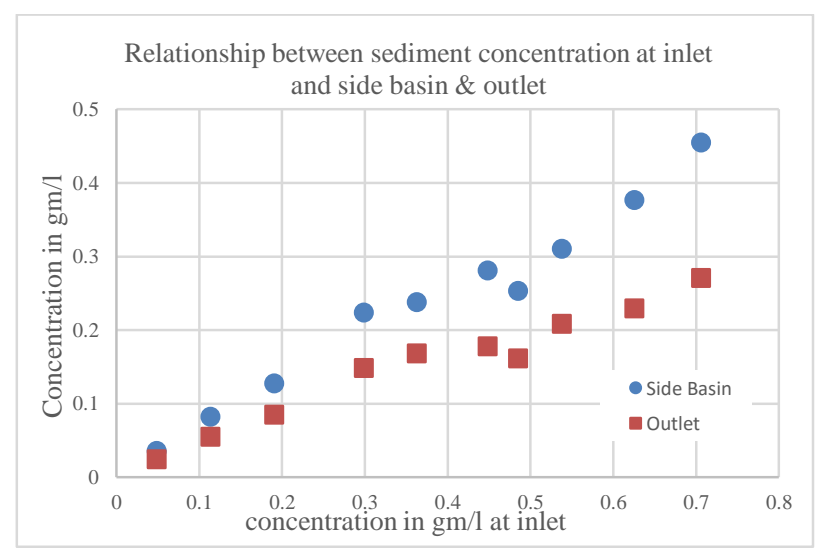

Fig.13 Sediment concentration at side basin and outlet Vs sediment concentration at inlet

With changing outflow discharge from side basin, sediment concentration at inlet (1-2-3) is almost constant. But it has significant effects in outlet (7-89) and side basin (4-5-6). Sediment concentration is increasing in side basin (4-5-6) whereas decreasing in outlet (7-8-9) with increase in discharge at side basin (Fig. 12). When higher outflow discharge is allowed to flow from side basin higher sediment is transported towards it and lesser sediment on the course of river.

Finally with varying sediment supply at inlet in sediment feeder, sediment concentration recorded at inlet has minimum value of $0.05 \mathrm{gm} / 1$ to maximum of $0.7 \mathrm{gm} / \mathrm{l}$ during experiment. It is obvious that increase in concentration at inlet will surely increase concentration at side basin and outlet. But distribution of sediment towards side basin to outlet is almost same in all conditions with ratio varying from $1.41-1.67$ particularly in this case with 50 1/min outflowed from side basin (Fig.13).

\section{DISCUSSIONS}

Transportation and deposition of suspended sediment mostly depends upon the direction of flow and magnitude of discharge. Change in final bed level elevation between two cases clearly shows shift of sediment deposition from river towards side basin. In real scenario of TBM, if direction of flow is made easy towards selected tidal beel more sediment can be transported and deposited.

Moreover with increase in outflow discharge towards side basin, sediment transportation and deposition also increases. From this it can be inferred that in those tidal basins where more flow passes have more sediment transport and deposition. This might happen due to either large size of tidal basin, larger 
water holding capacity of beel, steeper topography of beel, large size of opening of beel or proper orientation of intake of beel in tidal basin management.

Within the range of $0-0.7 \mathrm{gm} / 1$ sediment concentration at inlet, the distribution of sediment towards outlet and side basin seems almost same. Lateral widening of side basin doesn't happen in experimental flume therefore the ratio of sediment distribution is almost same for all types of sediment concentration at inlet from low to high. In reality when TBM is operated in selected beel, flow channels are laterally widened resulting more space for larger water and sediment discharge.

The current findings have some limitations of fixed bed, no tidal effect, constant inflow discharge, no lateral widening of side basin, shape of side basin etc. The results of this study are discussed in order to provide the qualitative and quantitative relationship between sediment transport with flow magnitude and direction. These results when interpreted in conjunction with numerical studies, other experimental studies or field based real data, provide important information for environmentally oriented design of hydraulics in river channels.

\section{CONCLUSIONS}

The present experimental work investigated the suspended sediment transport and deposition at side basin representing tidal beel to see the effectiveness of tidal basin management. A steady inflow scenario was tested with fixed bed condition. The outflow at side basin was changed from 0 to around $65 \%$ of inflow and sediment concentration was changed upto $0.7 \mathrm{gm} / \mathrm{l}$ which also covers the real scenario in Bangladesh.

From the experimental study it can be concluded that deposition of suspended sediment mainly depends upon direction of flow and magnitude of discharge. Field based data of size of tidal beel, topographical condition of beel, sediment concentration at river, tidal effects on discharge, lateral widening process of channel, average deposition of suspended sediment in operated tidal basin are very much important to understand the phenomena of TBM precisely.

Once the phenomena of sediment concentration at side basin and outlet in constant inlet discharge is understood, the test setup can be adapted to account for movable bed, change in size of side basin and change in discharge due to tidal cycle. The current findings have to be expanded in the next experiment and simultaneously have to be simulated numerically.

\section{ACKNOWLEDGMENT:}

The research is supported by JST/JICA SATREPS program on disaster prevention/mitigation measures against floods and storm surges in Bangladesh (PI: Dr. Hajime Nakagawa). The first author is pleased to acknowledge a Monbukagakusho (Ministry of Education, Culture, Sports, Science and Technology, Japan) scholarship for graduate students.

\section{REFERENCES}

1) Leender de Die 2013, MSc Thesis on Tidal River Management : Temporary depoldering to mitigate drainage congestion in the southwest delta of Bangladesh, Wageningen University, the Netherlands.

2) Hughes, R., Adnan, S., Dalal-Clayton, B. 1994. Floodplains or Flood Plans? A review of approaches to water management in Bangladesh.

3) Milliman, J.D. and Meade, R.H., 1983. World-wide delivery of sediment to the oceans. Geology. 91, 1-21.

4) Milliman, J.D. and Syvitski, J.P.M., 1992. Geomorphic/tectonic control of sediment discharge to the ocean: the importance of small mountainous rivers. Journal of Geology. 100, 525-544.

5) Bron, J. 1997. Water Management in the Bangladesh Context. Reader of Workshop on Integrated Water Resources Management, BUET 1997.

6) Md. Sharif Imam Ibne Amir, M. Shah Alam Khan, Mohammad Masud Kamal Khan, Mohammad Golam Rasul, Fatema Akram. 2013 Tidal River Sediment Management-A Case Study in Southwestern Bangladesh International Journal of Civil, Environmental, Structural, Construction and Architectural Engineering Vol:7, No:3.

7) Rahman M. R., 2008 "Investigation into Replicability of Good Practices in Flood Management," Institute of Water and Flood Management, Bangladesh University of Engineering and Technology, Dhaka, Bangladesh.

8) BUET: Bangladesh University of Engineering and Technology, Bangladesh Centre for Advanced Studies 2010. Interdisciplinary Research in Water Resources Management; Reader on Tidal River Management in Southwest Coastal Area. Conference in Dhaka and Khulna.

9) Asian Development Bank (ADB) 2007. Performance Evaluation Report: Bangladesh, Khulna-Jessore Drainage Rehabilitation Project. Operations Evaluation Department, Asian Development Bank.

10) SMEC; Snowy Mountain Engineering Corporation International 2002. Khulna-Jessore Drainage Rehabilitation Project: Project Completion Report.

11) IWM: Institute for Water Modelling 2010. Feasibility Study and Detailed Engineering Design for Long Term Solution of Drainage Problems in the Bhabodah Area.

12) Arora C. \& Bhaskaran P. K. 2013 Numerical modeling of suspended sediment concentration and its validation for the hoogly estuary, India.

13) Lane, E.W. \& Borland, W.M., 1951. Estimating bed load. American Geophysical Union Transactions. 32, 121-123. 